\title{
LA ALFABETIZACIÓN DE LOS MAYAS YUCATECOS Y SUS CONSECUENCIAS SOCIALES, $1545-1580$
}

\author{
Caroline Cunill \\ Université de Toulouse-Le Mirail
}

El encuentro entre motivaciones mayas y franciscanas acerca de la enseñanza

Cualquier aprendizaje es el fruto de un encuentro, el de dos grupos que tienen respectivamente motivaciones concretas para enseñar y aprender. En el caso del aprendizaje de la escritura alfabética por parte de los mayas yucatecos, el deseo franciscano de evangelizar a las nuevas poblaciones coincidió con el deseo maya de preservar su cultura gracias al conocimiento de la cultura hispana; y de allí nació la posibilidad de la enseñanza y del aprendizaje de la escritura alfabética.

\section{El concepto franciscano de evangelización}

Se expondrán brevemente, ya que no son específicas de Yucatán sino de la política educativa franciscana en general, las motivaciones de la orden seráfica para enseñar la lectura y la escritura a los indios. Primero, como observa Robert Ricard, en una sociedad de tipo teocrática "la enseñanza nunca puede hallarse separada de la educación. Por lo consiguiente la enseñanza de la doctrina y de la lectura y escritura van paralelas, se hallan íntimamente ligadas y son dadas a menudo por los mismos maestros". ${ }^{1}$ Por otra parte, la escasez de religiosos en América explica la necesidad de formar a indígenas capaces de prestar ayuda para evangelizar a otros nativos. ${ }^{2}$ La evangelización podía ser más eficaz si la llevaban a cabo indígenas en vez de europeos, pues aquellos inspiraban confianza ya que no estaban asociados con los conquistadores o "cristianos". Como dice Diego Briceño, Gaspar Antonio Chi, indio descendiente de la familia Xiu de Maní, "no pudo dejar de hacer gran fruto en ello entre los naturales indios de estas provincias y en especial viendo los dichos indios que persona de su natural les declaraba el

\footnotetext{
* Agradecemos a la doctora Manuela Cristina García Bernal y al doctor Patrick Lesbre cuyas sugerencias contribuyeron a la versión definitiva de este artículo.

${ }^{1}$ Ricard, La conquista espiritual de México, pp. 320-321.

${ }^{2}$ Véase el "Parecer de fray Alonso de Castro en favor de que se enseñen a los indios las artes liberales y la teología”, Salamanca, 1543. En Gómez Canedo, La educación de los marginados durante la época colonial: escuelas para indios y mestizos en la Nueva España, pp. 321-327.
} 
Santo Evangelio". ${ }^{3}$ El conocimiento de la lectura y de la escritura por parte de los indígenas era útil porque les permitía la memorización y la fácil consulta del credo y de la doctrina en las llamadas "cartillas de la doctrina cristiana".

Otra motivación que en general no se menciona y que, sin embargo, fue primordial para los franciscanos, fue su voluntad de aprender los idiomas nativos para poder predicar directamente, sin la ayuda de ningún intérprete. Para los franciscanos, este aprendizaje pasaba por la transcripción en caracteres latinos de los idiomas indígenas como primera etapa de su aprendizaje. Luego venía la "reducción a arte" (es decir, a reglas), según la expresión de la época. De acuerdo con el testimonio del cronista franciscano Bernardo de Lizana, el trabajo linguíśstico de los franciscanos permitiría que los religiosos recién llegados a la península pudieran aprender el maya yucateco en tan sólo dos meses. ${ }^{4}$ Para realizar estos trabajos linguísticos, los religiosos contaron en Yucatán con la valiosa ayuda del ya citado Gaspar Antonio Chi que "fue el primero que abezó la lengua de esta tierra y la pusieron en arte los religiosos" y "con él y por su lengua e interpretación [...] predicaban a los naturales el santo evangelio y es verdad que fue el primer intérprete de quien se ayudaron mucho los dichos religiosos". ${ }^{6}$ Nos damos cuenta de que la enseñanza de la escritura alfabética impartida a los mayas fue motivada tanto por el deseo de enseñar como por el de aprender. Con este doble objetivo, los religiosos prefirieron la escritura alfabética a la escritura maya, ya que suponía para ellos un menor esfuerzo. Sin embargo, nunca despreciaron la eficacia de la escritura prehispánica para transcribir la lengua maya yucateca. Refiriéndose a los naturales, fray Diego de Landa comenta en su Relación que éstos "usaban también de ciertos caracteres o letras $[. .$.$] y con estas figuras y algunas señales de las mismas entendían$ sus cosas y les daban a entender y enseñaban". ${ }^{7}$ Hasta algunos encomenderos escriben en las Relaciones Geográficas que "[los naturales] tenían letras con que escribían y se entendían, que eran caracteres que cada uno era una parte y por ella se entendían como nosotros con nuestras letras". ${ }^{8}$ Es muy probable que tal comentario tenga como origen a Gaspar Antonio Chi, el cual ayudó a los enco-

\footnotetext{
${ }^{3}$ Las probanzas de Gaspar Antonio Chi se encuentran en el Archivo General de Indias. La primera parte está dentro de la sección Audiencia de México, en el legajo 104, y la segunda en el legajo 105. Para un análisis de las probanzas de Gaspar Antonio, véase Hillerkuss, "Los méritos y servicios de un maya yucateco principal del siglo xvi y la historia de sus probanzas y mercedes", pp. 9-25.

${ }^{4}$ Lizana, Historia de Yucatán, Devocionario de Nuestra Señora de Izamal y conquista espiritual. Edición citada, pp. 164-165.

${ }^{5}$ Sebastián de Covarrubias define así el verbo abezar: "vale enseñar y acostumbrar; unos quieren que traiga su origen del a, b, c, que son las letras que primero se enseñan; pero lo mismo puede decirse de bezo, que es el labio de la boca $[\ldots]$ por ser instrumento de la pronunciación con que se enseña, y en la escritura se toma por lenguaje". Tesoro de la lengua castellana o española, p. 28.

${ }^{6}$ AGI, México, 104. "Probanza de Gaspar Antonio Chi".

${ }^{7}$ Diego de Landa, Relación de las cosas de Yucatán, p. 117.

${ }^{8}$ Relaciones histórico-geográficas de la Gobernación de Yucatán: "Relación de Dzidzontún, Susal y Chalante".
} 
menderos a responder a las preguntas del Memorial que se les había mandado por orden real en $1579 .{ }^{9}$

\section{El concepto maya de escritura}

Como se ha visto, las motivaciones de los franciscanos para alfabetizar a los indios eran profundas y diversas. Del mismo modo, los mayas tenían múltiples razones para interesarse en dicho aprendizaje. Ya tenían una escritura eficaz y bien arraigada, de manera que hubieran podido prescindir del método alfabético. La escritura prehispánica era "grafemática-logográfica", ${ }^{10}$ según la expresión de Patricia Martel y Edmundo de la Rosa. Se componía de glifos o "elementos visuales mínimos con significado" y cada glifo se caracterizaba por la asociación de una forma, un color y un espacio determinado, conformando "una escritura de la especialidad, la cual crea una estructura paralela a la lengua común". ${ }^{11}$ Esta práctica constituyó un terreno propicio para la alfabetización. En los primeros textos de los franciscanos, muchas veces encontramos referencias a la buena disposición y facilidad de los indios para aprender a leer y escribir en caracteres latinos. El hecho de que los mayas fueran tan receptivos a este tipo de aprendizaje también se puede explicar por el alto concepto que tenían de la escritura. Para ellos, dicha práctica tenía un valor sagrado, ya que permitía conservar la memoria de los acontecimientos que los sacerdotes o ah k'ines estaban encargados de salvaguardar e interpretar para entender el futuro. En el Libro de Chilam Balam de Chumayel hemos encontrado un fragmento ilustrativo de esa peculiar relación con la escritura:

Esto es la memoria de las cosas que sucedieron y que hicieron. Ya todo pasó. Ellos hablan con sus propias palabras y así acaso no todo se entienda en su significado; pero, derechamente, tal como pasó, así está escrito. Ya será otra vez muy bien explicado todo. Y tal vez no será malo. No es malo todo cuanto está escrito. ${ }^{12}$

Es difícil saber a qué escritos se referían los autores de este fragmento. Podemos suponer que hablaban de unos libros en escritura prehispánica que ya no se podían interpretar en la época en la cual se escribió este texto. Es interesante notar la confianza por lo escrito, a pesar de las dificultades de comprensión.

\footnotetext{
${ }^{9}$ Sobre las similitudes entre varios pasajes de las Relaciones Geográficas y la Relación de algunas costumbres de Gaspar Antonio Chi y sobre la posibilidad de que este último fuera la fuente de algunas declaraciones de los encomenderos, ver Jakeman, The historical recollections of Gaspar Antonio Chi. An early account of Ancient Yucatan, pp. 9-27.

${ }^{10}$ Nota del editor: actualmente sabemos que es silábica-logográfica.

${ }^{11}$ Martel y López de la Rosa, “Than-uooh. Experiencias con la escritura maya yucateca prehispánica”, pp. 93-108.

${ }^{12}$ Mediz Bolio, El libro de Chilam Balam de Chumayel, p. 30.
} 
El conocimiento de la escritura también era sinónimo de poder y de prestigio. Por esa razón los ah k'ines mayas eran tan respetados. ${ }^{13}$ Sin embargo, no era un requisito indispensable el saber leer y escribir para gobernar. De manera que la mayoría de los principales no lo hacían. Según Landa, sólo aprendían a leer y escribir los hijos de los sacerdotes y los hijos menores de los señores que se destinaban al oficio de sacerdote. ${ }^{14}$ Si nos fijamos en el Libro de Chilam Balam de Chumayel, encontramos una confirmación de esta hipótesis. Se habla de la sabiduría de los dirigentes, pero en ningún momento de su capacidad de leer o escribir. En el "Libro de las Pruebas", en el cual se profetiza el regreso al orden sociopolítico prehispánico, se hace referencia a la sabiduría de los príncipes de la manera siguiente: "Los nobles descendientes de los príncipes [...] verán que era su sabiduría la que tenía poder sobre sus vasallos". ${ }^{15}$ Parece que esta sabiduría descansaba más en la tradición oral que en la tradición escrita. Pensamos en el papel desempeñado por el lenguaje de Suyúa como prueba para seleccionar a los verdaderos dirigentes. ${ }^{16}$ Los comentarios de Gaspar Antonio Chi acerca de la administración de la justicia en tiempos prehispánicos son reveladores. Gaspar Antonio compara el funcionamiento de la justicia antes y después de la conquista. En tiempos prehispánicos, el escrito no contaba en los juicios: "[Estos naturales] no tuvieron costumbre de escribir cosas [...] deudas ni cartas misivas y para los pleitos servi[...] dichos procuradores que siempre asistían [...] [...]ssava entre ellos quedaba por rati[...]". ${ }^{17}$ Parece claro que la redacción de tratados por parte de los mayas para la justicia hispana constituye uno de los aspectos de su adaptación al sistema jurídico español y no una tradición prehispánica. ${ }^{18}$ Según

13 "The Yucatecan priests were considered to be the most religious, wise and learned people and those most extreme in ceremonies and rites and the greatest seriousness, because, as I said above, they had their kind of letters and their books and treatises of their idolatries and false religion." Relación de Tomás López (1612), transcrita y traducida al inglés por Tozzer en Landa's 'Relación de las cosas de Yucatán', Appendix B, p. 223.

${ }^{14}$ Landa, op. cit., p. 21, "[los sacerdotes] enseñaban a los hijos de los otros sacerdotes y a los hijos segundos de los señores que les llevaban para esto desde niños si veían que se inclinaban a este oficio".

${ }^{15}$ Mediz Bolio, op. cit., p. 43.

${ }^{16}$ El lenguaje de Suyúa era un lenguaje esotérico compuesto de enigmas que permitía seleccionar a los gobernantes legítimos. Véase Arzápalo Marín, "El lenguaje del poder entre los mayas antiguos", en Beristáin y Ramírez Vidal (comps.), La palabra florida. La tradición retórica indígena y novohispana, pp. 83-93.

${ }^{17}$ AGl, México, 110. "Relación de Gaspar Antonio Chi”, 1582, fol. 80. El documento original está roto; los corchetes indican que falta esta parte del texto. Tozzer tradujo al inglés y publicó el documento en Landa's Relación, op. cit., Apéndice C, pp. 230-232. Sin embargo, su transcripción es incompleta. Matthias Strecker y Jorge Artieda propusieron una reconstrucción de la relación a partir de una comparación con el texto de Gaspar Antonio contenido en La Historia de Yucatán de fray Diego López de Cogolludo. Veáse La Relación de algunas costumbres de Gaspar Antonio Chi, 1582, pp. 1-25. La reconstrucción de Strecker y Artieda es la siguiente: "Estos naturales no tuvieron costumbre de escribir cosas [referid]as ni cartas missivas y para los pleytos servi[an ... mu]chos procuradores que siempre asistían [al]... assava entre ellos quedava por Rata”.

${ }^{18}$ Sobre el uso de los códices en la justicia hispana por parte de los indios del centro de México, véase Ruiz Medrano, “Códices y justicia: los caminos de la dominación”, pp. 45-50. 
Landa, sólo algunos principales sabían leer y escribir en la época prehispánica y estos principales eran más respetados que los demás. ${ }^{19}$ Por consiguiente, si los dirigentes mayas empezaron a aprender a leer y escribir y, sobre todo, si empezaron a mandar a sus hijos a las escuelas de los franciscanos para que aprendieran a leer y escribir, fue más por voluntad de adaptarse al sistema colonial que por tradición prehispánica. Entendieron que para mantener su estatus social tenían que conocer la cultura de los recién llegados. Landa dice "en principio daban los señores de mala gana sus hijos, [...]; mas como comprendieron el negocio, los daban de buena gana". ${ }^{20}$ Según Pedro Bracamonte y Gabriela Solís, el poder político de la elite maya en el periodo colonial se sustentaba en tres elementos: el conocimiento de la cultura prehispánica, el conocimiento de la cultura impuesta y la administración de los recursos para la supervivencia de la comunidad. ${ }^{21}$

\section{El papel de los ahkines: ¿resistencia o cooperación?}

Como se ha dicho, en la época prehispánica los ahkines eran los responsables de la enseñanza, en general, y de la enseñanza de la lectura y la escritura, en particular. ${ }^{22}$ Podemos preguntarnos cuál fue su actitud frente a la enseñanza de los religiosos. A este respecto, encontramos en los textos de los franciscanos numerosas referencias al papel negativo desempeñado por los ahkines mayas. Lizana explica el rechazo inicial de los indios a la enseñanza de los frailes por la fuerte influencia que tenían los sacerdotes sobre la población en esas fechas tempranas:

Pidiéndoles el bendito comisario [fray Luis de Villalpando] a los caciques y señores que le enviasen sus hijuelos allí a Mérida, y que de allí les enseñaría la doctrina cristiana, y a leer y escribir en los castellanos caracteres, y aunque dijeron que lo harían, después no quisieron hacerlo, porque los sacerdotes de los ídolos les persuadieron que no era para enseñarlos el pedir los muchachos sino para sacrificarlos y comérselos, o venderlos fuera de la tierra, como los cristianos lo hacían al principio. ${ }^{23}$

Podemos suponer que los sacerdotes pensaron que los religiosos representaban una amenaza para su propio oficio y, por consiguiente, para su posición social. Sin embargo, no olvidemos que Gaspar Antonio Chi, el más famoso de los indios ladinos, conocedor de la lengua castellana y hasta versado en latín, era hijo de un sacerdote. Según la Crónica de Oxkutzcab y el Informe contra idolatrorum

${ }^{19}$ Landa, op. cit., p. 21.

${ }^{20}$ Ibid., p. 38.

${ }^{21}$ Bracamonte y Solís, Espacios mayas de autonomía. El pacto colonial en Yucatán. Acerca del conocimiento especializado considerado como mecanismo de acceso al poder, véase también Solís Robleda, "Religión y sociedad maya al tiempo de la conquista", pp. 5-22.

${ }^{22}$ Landa, op. cit., p. 21.

${ }^{23}$ Lizana, op. cit., p. 149. 
cultores de Pedro Sánchez de Aguilar, era hijo del ahkin Chi. ${ }^{24}$ Además, debemos tener en mente que su alfabetización no implicaba el abandono de su propia escritura. En efecto, la desaparición de la escritura maya no fue tan rápida como se suele pensar, ya que a lo largo del siglo xvI la Iglesia siguió encontrando y quemando códices. ${ }^{25}$ Por otra parte, el progresivo abandono de la escritura prehispánica no fue sólo consecuencia de la aparición de un nuevo sistema, aunque, como lo nota Landa, sí debió ser un factor importante, ya que los muchachos dejaron de aprender la antigua forma de escribir. ${ }^{26}$ Esta desaparición fue más bien el resultado de la persecusión sistemática que empezaron a sufrir los sacerdotes en el último tercio del siglo xvi. Así que en un principio los sacerdotes no debieron pensar que la nueva escritura impediría el mantenimiento de su propio sistema cultural y tal vez hasta creyeron que podría reforzarlo y reforzar su propia posición en la sociedad. Si consideramos lo que representaron y siguen representando los libros de Chilam Balam para la supervivencia de la cultura maya, podemos decir que no se equivocaron.

Todo ello nos conduce a pensar que los religiosos tendieron a exagerar la influencia negativa de los sacerdotes en el proceso de evangelización de los mayas. No olvidemos que para los franciscanos los sacerdotes indios también representaban una competencia en el campo espiritual. Por eso debemos matizar las acusaciones de los franciscanos en contra de los sacerdotes indios. Al final, algunos de ellos habían mandado a sus hijos a las escuelas de los franciscanos y habían aprendido de buena gana la nueva escritura. Recordemos que Landa colaboró con mayas principales y es de suponer que entre sus colaboradores también había sacerdotes. Lo cual es lógico pues, siendo personas cultas, más fácilmente podían ser doctrinados y, siendo muy respetados, también más fácilmente podían doctrinar a los demás indios. El sacerdote Francisco Euan del pueblo de Caucel se convirtió y fue bautizado, y fue el mismo adelantado Montejo su padrino. Eso nos dice el propio Lizana:

Era este Francisco Euan de más de cincuenta años de edad, y aprendió a leer y escribir, y tenía tan buena persuasiva que no platicó con los yucatecos vez alguna en cosas de la fe que no los persuadiese a que le recibiesen, y como era tenido por sabio entre ellos en sus ciencias, y gran sacerdote de los ídolos, creían ser verdad lo que les decía, y de muy buena voluntad se convertían, y acudían a la doctrina sin ser llamados. Murió este cacique el año de $1560 .^{27}$

Landa, por su parte, no acusa a los sacerdotes en el aspecto de la enseñanza. Como obstáculo para ella, sólo se refiere al miedo que tenían los indios a los

${ }^{24}$ Blom, "Gaspar Antonio Chi, interepreter", pp. 250-262.

${ }^{25}$ Chuchiak, "Pre-conquest ah kinob in a colonial World: the Extirpation of Idolatry and the Survival of the Maya Priesthood in Colonial Yucatan, 1563-1697", 50th International Congress of Americanists: Five Hundreds Years of Maya Survivalism.

${ }^{26}$ Landa, op. cit., p. 119.

${ }^{27}$ Lizana, op. cit., p. 151. 
españoles. Landa únicamente los acusa en los casos más tardíos de idolatría. ${ }^{28}$ Así, parece que en un primer momento los sacerdotes mayas y los religiosos llegaron a un acuerdo para la enseñanza. Sólo más tarde, después de los juicios inquisitoriales de Maní, los frailes empezarían a desconfiar de ellos y en adelante no dejarían de hacerlo, como lo demuestran las incesantes acusaciones de Lizana que escribe en la primera mitad del siglo xvII. En ese momento, los sacerdotes se habían convertido en un obstáculo para la conversión de los indios, ya que preservaban su memoria religiosa. ${ }^{29}$ Es interesante notar que en su probanza, escrita en los años 1580, Gaspar Antonio Chi no se refiere explícitamente a su filiación con un sacerdote prehispánico, a pesar de ser de noble linaje, lo que confirma el clima de desconfianza hacia este grupo social en este momento de la historia colonial.

\section{La organización franciscana de la enseñanza y la cooperación maya}

El aprendizaje de la escritura por parte de los mayas yucatecos sólo fue posible gracias a la cooperación maya. De forma que la enseñanza en Yucatán fue marcada tanto por los métodos franciscanos como por las tradiciones mayas y su propia cultura de la enseñanza.

Las escuelas cerca de los monasterios

La enseñanza de los indios en la Nueva España no fue algo improvisado por los franciscanos, sino que respondió a un proyecto bien pensado, respaldado tanto por el papa como por los reyes de España. ${ }^{30}$ Las primeras experiencias de enseñanza se llevaron a cabo en el centro de México desde 1524 con la llegada de la misión de los "Doce", quienes también pudieron aprovechar la experiencia de los franciscanos que ya llevaban algunos años en Nueva España. ${ }^{31}$ En 1537, fray Jacobo de Testera entró en Yucatán pero, dada la inestabilidad de la provincia, tuvo que retrasar la instalación definitiva de los religiosos. Fue fray Luis de Villalpando, acompañado por fray Melchor de Benavente, fray Juan de Herrera y fray Lorenzo de Bienvenida, quien estableció de manera definitiva la orden será-

${ }^{28}$ Ibid., p. 39.

${ }^{29}$ Para un análisis detallado de lo que representaron los juicios inquisitoriales de Maní en la historia de las relaciones entre mayas y españoles, véase Clendinnen, Ambivalent Conquest: Mayas and Spaniards, 1517-1570.

${ }^{30}$ Para una visión general del trabajo de enseñanza en América, véase Rodríguez Lorenzo, "Un capítulo de la historia de la escritura en América: la enseñanza de las primeras letras a los indios en el siglo xvl", pp. 41-64.

${ }^{31}$ Para un estudio de la educación en el centro de México, véanse Ricard, op. cit., y Gómez Canedo, op. cit. Véase también Gómez Canedo, Evangelización y conquista: experiencia franciscana en Hispanoamérica. 
fica en la provincia de Yucatán a partir de finales del año $1544 .{ }^{32}$ Como lo había hecho Hernán Cortés en el centro de México, Francisco de Montejo el Mozo recibió con muchos honores a los frailes en Campeche. Los caciques y principales indios fueron reunidos y los religiosos les explicaron la naturaleza de su misión y les pidieron que mandaran a sus hijos para recibir instrucción religiosa. ${ }^{33} \mathrm{Se}$ puede observar que la instrucción de los niños constituía uno de los principales objetivos de los frailes. Antes de que se construyeran iglesias o monasterios, los hijos de los caciques podían recibir la enseñanza de los frailes en las casas de éstos. Fray Toribio Motolinía dice que: "los [franciscanos] que quedaron en la tierra recogieron en sus casas a los hijos de los señores principales, y bautizaron muchos con voluntad de sus padres. Estos niños, que los frailes criaban y enseñaban, salieron muy bonitos y muy hábiles". ${ }^{34}$

La primera escuela de Yucatán fue fundada en Campeche. Fue fray Juan de Herrera, hermano lego, quien se encargó de la enseñanza. Luego fray Luis de Villalpando y fray Lorenzo de Bienvenida se trasladaron a Mérida donde fundaron una iglesia y un convento. También invitaron a los caciques a que mandaran a sus hijos. Fray Juan de Herrera se trasladó posteriormente a Mérida para encargarse de la enseñanza, como lo había hecho en Campeche. Es de suponer que otro religioso tomó su puesto en Campeche, pero las fuentes no precisan quién fue. La tercera escuela fue fundada en Maní, junto al convento, entre 1547 y 1549. Acerca de la escuela de Maní, encontramos en Lizana una referencia que nos informa sobre la estructura de esos conjuntos arquitectónicos que formaban iglesias, conventos y escuelas: "Fray Juan de Mérida [construyó] el convento de Maní, con iglesia y capilla mayor, claustro y dormitorios y cerca dentro, y fuera con todo menester de Sacristías, y otra capilla mayor de indios, y patio y portadas y escuelas". ${ }^{35}$ El plural escuelas nos indica que la enseñanza se hacía a gran escala. Lizana dice que en Mérida fray Juan de Herrera instruyó a un grupo de más de mil niños. ${ }^{36}$ Es lícito pensar que cada vez que se construía un convento también se construía una escuela o que la escuela estaba integrada al conjunto arquitectónico mismo de los monasterios. En el proceso contra Francisco Hernández hemos encontrado un dato interesante acerca de este tema. Se reprocha a este vecino de Valladolid el haberse opuesto a que los indios del pueblo de su encomienda siguieran construyendo la "casa" para los muchachos que estudiaban en el monasterio de Sisal. ${ }^{37}$ Por otra parte, en el proceso contra Gregorio Valdivia,

\footnotetext{
32 Para más detalles sobre el establecimiento y la organización de los franciscanos en Yucatán, véase González Cicero, Perspectiva religiosa en Yucatán, 1517-1571.

${ }^{33}$ Lizana, op. cit., cap. 5.

${ }^{34}$ Motolinía, Historia de los indios de la Nueva España, p. 62.

${ }^{35}$ Lizana, op. cit., p. 222.

36 Ibid., p. 150.

37 "y porque los indios de su pueblo venían a hacer una casa para estos muchachos [del monasterio de Sisal] el dicho Francisco Hernández impidió que no la hiciesen.” Proceso contra Francisco Hernández ante la Inquisición ordinaria por ofensas a los religiosos franciscanos, 1556-1562. En Rubio Mañé, Archivo de la historia de Yucatán, Campeche y Tabasco, II.
} 
de los cuarenta tostones a los cuales se le condenaba, veintidós se destinaron "a los indios de la escuela de este monasterio [el de la Madre de Dios] por estar necesitados para que comprasen maíz con que comer" ${ }^{38}$ Podemos pensar que en la forma de concebir el espacio de los conventos, se mezclaron las tradiciones hispanas con las prehispánicas. Juan García Targa y Alfonso Gussinyer, al analizar los primeros templos cristianos que se construyeron en Yucatán, se refieren más ampliamente a la "americanización del tradicional templo cristiano", ya que se logró "adaptar la tradicional liturgia cristiana a un culto a cielo abierto sin perder valor como tal". ${ }^{39}$ Los niños que asistían a las clases eran acompañados por miembros de su comunidad, quienes también les daban de comer. Landa dice al respecto:

La manera que se tuvo para adoctrinar a los indios fue recoger a los hijos de los señores y gente principal poniéndolos en torno de los monasterios en casa que cada pueblo hacía para los suyos, donde estaban juntos todos los de cada lugar cuyos padres y parientes les traían de comer. ${ }^{40}$

Esta colaboración era necesaria, dada la falta de respaldo económico de los religiosos en la región. Los encomenderos no querían respaldar el adoctrinamiento de los indios que tenían en encomienda, tarea que, sin embargo, les correspondía. Marcos de Ayala Trujeque constituyó una excepción ya que mandó a algunos muchachos de su encomienda a estudiar con los religiosos en Mérida. Una vez instruidos, esos muchachos regresaron a su pueblo para enseñar a los demás niños. ${ }^{41}$ En estas condiciones, los franciscanos debían contar necesariamente con la cooperación de los indios. Si creemos a Lizana, en la construcción del convento de Maní trabajaron seis mil indios durante siete meses. ${ }^{42}$ Es lícito preguntarse si esta participación de los indios fue completamente libre y voluntaria o si fue consecuencia de la compulsión que ejercieron los religiosos sobre ellos. Según Inga Clendinnen, la experiencia de los franciscanos en el Nuevo Mundo y su relación continua e íntima con los indios modificó la ideología que tenían los religiosos al llegar y el empleo de la violencia se convirtió en uno de los métodos misionales, justificado por la relación de padre a niños establecida con los indios. ${ }^{43}$

\footnotetext{
38 Proceso contra Gregorio Valdivia, 1560, ibid., I.

${ }^{39}$ García Targa y Gussinyer, "Los primeros templos cristianos en el área maya: Yucatán y Belice, 1545-1585", pp. 95-119.

${ }^{40}$ Landa, op. cit., p. 36.

${ }^{41}$ Solís Robleda, en prensa. Agradecemos a la doctora Solís Robleda la comunicación de este interesante caso.

42 Lizana, op. cit., p. 223.

${ }^{43}$ Clendinnen, "Disciplining the Indians: Franciscan Ideology and Missionary Violence in Sixteenth Century Yucatan”, pp. 27-48.
} 
El maestro franciscano más conocido fue fray Juan de Herrera. Desgraciadamente, se sabe poco acerca de su vida ${ }^{44}$ y de su trabajo, ya que no se encontraron testimonios directos de dicho fraile, que no participó tan activamente en la defensa de los indios yucatecos como otros religiosos conocidos por su ardiente defensa de los indios como fueron fray Luis de Villalpando o fray Lorenzo de Bienvenida. ${ }^{45}$ Podemos suponer que, como los demás frailes que llegaron con él a Yucatán, ya tenía experiencia de la enseñanza que los franciscanos impartían a los indios en el centro de México desde hacía cerca de veinte años. Es probable que los franciscanos llegaran a Yucatán con material para la enseñanza que traían del centro de México, como cartillas o doctrinas, tal vez en lengua náhuatl y castellana, ya que las primeras doctrinas bilingüies se imprimieron en México a principios de la década de $1540 .{ }^{46}$ Así podríamos interpretar la referencia que hace Lizana sobre el material que usaba fray Juan de Herrera para enseñar la lectura y la escritura a los mayas yucatecos: "El primero que enseñó a cantar a los indios, el primero que les puso caracteres castellanos en las manos, y les hizo que leyesen y escribiesen, y les enseñaba la doctrina en latín fue este santo varón [fray Juan de Herrera]". ${ }^{47}$

Respecto a la obra de fray Juan de Herrera, la única referencia que tenemos se encuentra en un manuscrito redactado por el padre Juan Pedro de Herrera. Ruth Gubler descubrió este manuscrito en 1983 en la Biblioteca Crescencio Carrillo de la ciudad de Mérida. El padre Juan Pedro de Herrera dice que el vocabulario que contiene su libro fue copiado de un viejo manual de fray Juan de Herrera. ${ }^{48}$ También atribuye a fray Juan de Herrera la lista de plantas que viene en dicho manuscrito. Por otra parte, el manuscrito comprende traducciones al maya del pater noster, del avemaría y del credo. En realidad, sabemos por los testimonios de los cronistas que los religiosos escribieron numerosas doctrinas en maya. Según Lizana, uno de los primeros en traducir sermones al maya fue fray Luis de Villalpando. ${ }^{49}$ Como ya hemos señalado, Villalpando y los primeros religiosos contaron para esta tarea con la ayuda de Gaspar Antonio Chi. Sin embargo, cuando los criollos empezaron a ingresar en la orden de San Francisco, también

\footnotetext{
${ }^{44}$ Véase la carta de fray Antonio de Tarancón al reverendo padre fray Francisco de Bustamante, comisario general de la Orden de San Francisco en Nueva España. Mérida, 26 de febrero de 1563, en Don Diego Quijada, alcalde mayor de Yucatán, II, pp. 22-23. En adelante DDQAMY.

${ }^{45}$ A propósito de la defensa del indio yucateco, véase García Bernal, "Los franciscanos y la defensa del indio yucateco", pp. 8-16. Véase también "Indios y españoles en Yucatán: utopía del proyecto colonizador", en Historia del Descubrimiento (1492-1556), II, pp. 387-427.

${ }^{46}$ García Icazbalceta, Bibliografía mexicana del siglo xvı.

${ }^{47}$ Lizana, op. cit., p. 203.

48 "Está escrito de acuerdo con un viejo manual e opusculo oposculorum de fray Juan de Herrera que vivió en el cacigazgo de los Xiu y que luego se pasó el resto de su vida peregrinando por estas Provincias." Gubler, "Manuscrito inédito del padre Juan de Herrera", pp. 25-29.

${ }^{49}$ Lizana, op. cit., p. 142.
} 
participaron en el trabajo linguístico, dado que el maya yucateco era su lengua materna. Lizana nos informa, por ejemplo, que fray Juan Velázquez "era excelente lengua yucateca por ser criollo y por haber trabajado con los maestros de la lengua que de España vienen [...] y ha escrito muchos sermonarios y vocabularios". De la misma manera, fray Alonso de Solana "fue maestro de la lengua de esta provincia y escribió en ella mucha doctrina, y sermonarios, y vocabularios". ${ }^{50}$ A pesar de esta inmensa labor, sólo una doctrina cristiana en maya yucateco llegó a imprimirse en 1575 en México, gracias a los trámites de fray Diego de Landa. ${ }^{51}$ En definitiva, y a diferencia de lo que pasó con otras regiones de la Nueva España en las cuales se imprimieron vocabularios y doctrinas en las lenguas indígenas en náhuatl, tarasco, zapoteco y mixteco, ${ }^{52}$ en Yucatán muchas obras de mano circulaban, pero pocas se imprimieron y menos llegaron hasta nosotros, lo que hace más difícil el conocimiento de los métodos usados por los frailes en Yucatán para enseñar y adoctrinar a los indios.

\section{La formación de los maestros franciscanos}

Los franciscanos no sólo pensaron elaborar material para facilitar la enseñanza de los indios: también pensaron formar a los religiosos que se destinaban a su enseñanza. Uno de los aspectos más importantes en el programa de esta formación era el aprendizaje de la lengua maya yucateca. Se hacía gracias a las "artes" o reglas que los primeros frailes habían compuesto y que los demás religiosos siguieron perfeccionando. Los estudiosos, apoyándose en citas de Lizana y Cogolludo, suelen atribuir a Villalpando un vocabulario maya que habría desaparecido. ${ }^{53}$ René Acuña, apoyándose en la ya citada carta de Landa de 1578 , piensa que este arte nunca fue impreso. Según este estudioso, la primera arte maya fue impresa por fray Juan Coronel en 1620. La obra de Juan Coronel incluía, aparte del Arte en lengua maya, una Doctrina christiana, "presumiblemente la misma que publicó Landa en 1575”, y Discursos predicables que seguramente procedían de los "sermones de mano" que circulaban en la región. ${ }^{54}$

Para llevar a cabo tan importante y ardua tarea linguí́stica, fray Luis de Villalpando contó con la ayuda de colaboradores. Ya hemos mencionado a Gaspar Antonio Chi. Tampoco debemos olvidar a fray Jerónimo de Contreras. Según consta en su probanza de méritos, Jerónimo de Contreras desempeñó con respecto a los religiosos de Yucatán un papel similar al de Alonso de Molina en el centro

${ }^{50}$ Ibid., pp. 221-226.

${ }^{51}$ Véase Acuña, "Escritos mayas inéditos y publicados hasta 1578: testimonio del obispo Diego de Landa”, pp. 165-179. El artículo contiene la reproducción y la transcripción de la carta de Landa.

52 García Icazbalceta, op. cit., p. 41.

53 "No aparece en este catálogo el vocabulario maya del padre Villalpando, franciscano, porque no lo he visto, no encuentro su descripción; mas parece no haber duda de su existencia" (Ibid., nota 117, p. 41).

${ }^{54}$ Acuña, op. cit., pp. 169-170. 
de México. Los dos eran jóvenes criollos cuando empezaron a ayudar a los religiosos en trabajos linguiísticos y los dos acabaron ordenándose frailes. Según su probanza, fray Jerónimo de Contreras "[fue] el primero que ayudó a poner la lengua de los naturales de Yucatán en arte". ${ }^{55}$ Estas artes fueron las que permitieron enseñar a los religiosos recién llegados de España el idioma maya yucateco.

Todos los franciscanos que llegaban a Yucatán desde España recibían una formación lingüística para que sin tardar pudieran predicar a los indios. ${ }^{56}$ Esta formación la impartían algunos franciscanos que llegaron a especializarse en la enseñanza de los demás religiosos. Solían ser los más experimentados y diestros en la lengua yucateca. Sabemos, por ejemplo, que fray Luis de Villalpando fue maestro de fray Diego de Landa, quien a su vez fue maestro de otros frailes. Finalmente, señalaremos que esta formación dedicada a los mismos religiosos se llevaba a cabo en el convento de Izamal. Lizana nos informa que "[allí fueron] llevados los religiosos que de España venían a que se les enseñase la lengua yucateca". ${ }^{57}$ Así nos damos cuenta de la eficacia de la organización franciscana. Toda una jerarquía estaba establecida. De esta manera aprovechaban al máximo las capacidades y habilidades de cada religioso. En esta minuciosa organización, los franciscanos también concebían un espacio específico para los mayas: el de enseñar la doctrina a los niños en los pueblos de indios que no tenían conventos.

\section{Autonomía maya en el campo de la enseñanza}

Dado su escaso número en comparación con el de los indios por evangelizar, los religiosos tuvieron que confiar parte de dicha tarea a algunos mayas selectos y formados para ello. Así nacieron las funciones de maestro y mozo de escuela en los pueblos de indios. Sin embargo, los mayas usaron la autonomía concedida para conservar sus propias tradiciones, lo que llevó al violento conflicto con los franciscanos conocido como los juicios inquisitoriales de Maní de 1562.

Maestros mayas en los pueblos de indios: formación y repartición

En un principio, la autonomía de los indios en materia de enseñanza religiosa constituía un objetivo para los franciscanos. Los religiosos eran pocos y querían apoyarse en los indios para poder dedicarse a tareas que no querían delegar, como la formación de los religiosos recién llegados de España, la administración de los sacramentos, la defensa de los derechos de los indios y la conversión de indios infieles. Un comentario de Lizana acerca de la vida de fray Francisco de la Torre es explícito a este respecto:

\footnotetext{
55 AGl, México, 286. "Probanza de fray Jerónimo de Contreras, 1572".

${ }^{56}$ Lizana, op. cit., p. 164.

57 Ibid., p. 212.
} 
Y dejando ordenado a los fiscales de doctrina indios lo que habían de hacer para enseñar a los niños la doctrina cristiana, enfaldaba su hábito y con calces o alpargatas y su váculo en la mano y su brevario en la manga, acompañado de un indio que le guiaba se iba a los montes y ranchos donde había indios que aún no estaban reducidos a la santa fe católica. ${ }^{58}$

En el sur de Chile los jesuitas utilizaron un método misional similar. Formaban a fiscales de doctrina y les encargaban el cuidado de las iglesias y de los naturales mientras ellos se dedicaban a otras misiones. En las fuentes que hemos manejado, no hemos encontrado referencias que permitieran distinguir las funciones de fiscal y de maestro de escuela. En realidad, podría ser que fueran bastantes similares. En el caso de Chile, la palabra más corriente era la de fiscal, mientras que en Yucatán era la de maestro de escuela. ${ }^{59}$

Los religiosos formaban a algunos mayas en los monasterios y los mandaban a su pueblo de origen o a otros pueblos bajo el dominio colonial para que enseñaran, a su vez, la doctrina a los niños. Mientras tanto, podían dedicarse a la tarea puramente misional de evangelización de los pueblos fuera del control colonial. Los juicios inquisitoriales de Maní de 1562, publicados por Scholes y Adams en Don Diego Quijada alcalde mayor de Yucatán, contienen testimonios acerca de la distribución de los maestros de escuela en las provincias de Maní y Sotuta. En todos los pueblos de indios citados había un maestro de escuela que sabía leer y escribir y que pudo firmar los autos junto con el escribano y el intérprete. También en algunos casos se indica de dónde era natural el maestro de escuela, dónde fue formado y adónde fue mandado por los religiosos. El maestro de escuela Lorenzo Cocom era natural de Maní, fue formado allí mismo y mandado al pueblo de Yaxcaba por los religiosos. ${ }^{60}$ Juan May, maestro de escuela en Tibolon, también había sido formado en otro pueblo. Desgraciadamente, en este caso no se precisa en qué pueblo fue formado, tal vez porque se diera por sentado que procedía del monasterio de Maní: "Puede haber diez meses que este testigo [Juan May] es maestro en el dicho pueblo [Tibolon] y enseña a los muchachos de él porque le enviaron allí los religiosos a que enseñase". ${ }^{61}$

En la provincia de la Chontalpa los maestros de escuela hasta contribuyeron a la conversión de los indios fugitivos de la montaña. ${ }^{62}$ En 1566 don Pablo Paxbolón, gobernador del pueblo de Tixchel, recibió la visita de fray Francisco de Toral.

58 Ibid., p. 213.

${ }^{59}$ Para más información sobre las "misiones volantes" de los jesuitas en Chile y el papel de fiscal en esa área, véase Moreno Jería, "Metodología misional jesuita en la periferia austral de América”, Hernández Palomo y Moreno Jería (coords.), La misión y los jesuitas en la América Española, 1566-1767: cambios y permanencias, pp. 239-263.

60 DDQAMY, I, p. 112. Véase en nuestro apéndice los cuadros 1,2 y 3.

${ }^{61}$ Ibid., I, p. 125.

62 Para un análisis de la zona de emancipación llamada la montaña y las repercusiones políticas que tuvo en la zona maya bajo el control colonial, véase Bracamonte y Sosa, La conquista inconclusa de Yucatán. Los mayas de la montaña, 1560-1680. 
El obispo de Yucatán le pidió que trajera al conocimiento de Dios a los indios montaraces de dicha zona. Para conseguirlo, don Pablo organizó tres entradas a la montaña entre 1566 y 1568 . Entre los métodos que utilizó para reducir a los indios fugitivos destaca el envío de "dos mozos de la escuela a predicarles y decirles las oraciones en su lengua". Esta preparación servía para "reducir y quietar a los indios" y prepararlos para el bautismo que les administraría fray Juan de Santa María, "de forma que hoy en día son cristianos y están en paz en el dicho pueblo que se llama desde entonces Zapotitlan". ${ }^{63}$ Los mozos de escuela tenían a su cargo el trabajo de preparación espiritual de los indios montaraces. Sólo después de esta formación se mandaba a un religioso para administrar los sacramentos. Esta técnica se puede explicar por la renuencia de los indios montaraces a recibir españoles, tanto civiles como religiosos, en esta zona fuera de control colonial. ${ }^{64}$ Así comprobamos el grado de autonomía al que llegaron algunos mozos de escuela en el campo de la enseñanza, ya que se les confió la evangelización de pueblos de indios fuera de control colonial. De tal modo, en todos los pueblos citados en las declaraciones de 1562 se encontraban escuelas y maestros de escuela indios, algunas veces asistidos por mozos de escuela. Sin embargo, podemos preguntarnos cómo los franciscanos quisieron repartir exactamente los papeles y si los mayas no trasgredieron la organización franciscana, adquiriendo progresivamente más autonomía de la que se les asignaba.

Más allá del papel asignado: el conflicto con los religiosos

Los juicios inquisitoriales de Maní de 1562 pusieron de relieve la participación masiva de los maestros de escuela mayas en las ceremonias de corte prehispánico. Esta complicidad de sus alumnos con los idólatras constituyó una de las mayores razones de la decepción de los religiosos que habían confiado en ellos parte de la tarea de conversión. Este sentimiento aparece claramente en una carta de Diego de Landa del 9 de junio de 1562, en la cual acusa a los caciques y a los maestros de escuela de ser responsables de los brotes de idolatría:

A causa de no lo ser [fieles cristianos] algunos de sus caciques y principales y maestros de escuela de quien pende todo su bien por hacerse como se ha hecho confianza de ellos haciéndolos casi compañeros de los religiosos en la predicación e instrucción de los naturales en las cosas de nuestra santa fe católica. ${ }^{65}$

¿Cómo explicar la actitud de los maestros de escuela? Tal vez la misión que les habían confiado los religiosos era difícil de cumplir en el contexto sociopo-

63 AGl, México, 138, Ramo 4, N. 62. Papeles Francisco Maldonado.

${ }^{64}$ En efecto, cuando los indios de la montaña se enteraron de que don Pablo había revelado su existencia a los españoles, "le respondieron tristemente por haberlos descubierto al dicho padre y a los españoles diciéndole que si él los quería ver y tratar había de ser entre ellos solos”. AGı, México, 138. Papeles Paxbolon-Maldonado.

65 DDQAMY, I, p. 189. 
lítico de los pueblos de indios a los cuales eran mandados. En efecto, después de su formación, los maestros de escuela se encontraban solos en los pueblos de indios en los cuales las autoridades tradicionales seguían teniendo poder político y prestigio. En esas condiciones, propagar las nuevas creencias era casi imposible. Varios testimonios de maestros de escuela muestran la presión social que ejercían sobre ellos las autoridades indígenas tradicionales. En 1562, Juan Couoh, natural del pueblo de Tanuz, trabajaba como maestro en el pueblo de Yaxcaba. Un día lo llamó el cacique de este pueblo, Diego Pech, para que leyera una carta y participara en el sacrificio de un muchacho. Como Juan Couoh se negó, el cacique del pueblo le recordó que lo había sustentado e intentó hacerle sentir culpable. Por su parte, el ahkin del pueblo amenazó con matarlo. Un aspecto interesante de este testimonio es la referencia al hecho de que el cacique hubiera sustentado al maestro de escuela durante su formación:

Y como llegó este testigo el dicho cacique Diego Pech le dijo: [...] ¿No sabes tú que estoy ocupado y me debes mucho y mientras estuviste [...] te sustenté yo? Y a estas pláticas este testigo respondió que era verdad que todo aquello había hecho para este testigo y lo conocía. Y el dicho cacique le dijo: ¿cómo lo pagas tan mal que no quieres ayudarnos y nos andas revolviendo con los religiosos a los cuales no creas, que no puedes ser tú hijo de ellos ni te han de tener en lugar de hijo ${ }^{66}$

Desgraciadamente, una parte del texto es ilegible. Sin embargo, es lícito pensar que el cacique de Yaxcaba sustentó al maestro de escuela Juan Couoh durante su formación con los religiosos. Por eso le pide reconocimiento. Lo cual podía ser cierto pues, como ya vimos, Landa explicaba que eran los mismos indios y no los religiosos los que sustentaban a los alumnos de los frailes. ${ }^{67}$ Que Juan Couoh asistiera al sacrificio en la iglesia era una manera de comprometerle con los que participaban en la ceremonia y de forzarle a que elijiera el campo de los mayas y dejara el de los religiosos. Eso muestra la presión a la que eran sometidos los maestros de escuela mayas. Recibían de los religiosos una educación cristiana pero, de vuelta a sus pueblos, los caciques y los ahkines hacían lo posible para que se incorporaran de nuevo al mundo maya. Algunas veces, los maestros de escuela hasta recibían dos formaciones: además de su formación con los franciscanos, tenían una formación de sacerdote maya tradicional. Tal fue el caso de Juan Pech, maestro de escuela del pueblo de Usil, que en su declaración "dijo que [...] puede haber cuatro años, poco más o menos, que [...] es maestrescuela en el dicho pueblo y tiene cargo de enseñar a los muchachos, de lo que en este tiempo aprendió a ser ahkin y sacerdote". ${ }^{68}$

En la mente maya, la figura del maestro de escuela, con su capacidad de leer y escribir, se parecía mucho a la antigua figura del ahkin. Por eso esta función

${ }^{66}$ Ibid., I, p. 106.

${ }^{67}$ Landa, op. cit., p. 36.

68 DDQAMY, I, p. 114. 
introducida por los españoles llegó a ser recuperada por los mayas y adaptada a su propia organización sociopolítica. Otro ejemplo significativo de esta tendencia de los maestros de escuela mayas por desempeñar las funciones del ahkin prehispánico es el de Diego Tzab, hijo del cacique del pueblo de Sanahcat. Este último recibió una carta del cacique de Telchac, Francisco Pech, en la cual se le explicaba las antiguas tradiciones para que no las olvidara. En este caso no sabemos si el cacique Francisco Pech escribió personalmente la carta o si la mandó escribir al maestro de escuela de su pueblo. Naturalmente el cacique confió esta carta al maestro de escuela, su hijo:

...la cual leyó el declarante y vió que por ella decía el susodicho al dicho su padre las cosas antiguas [...] diciéndole que tuviese éstos en la memoria y no los olvidase y que tuviese por sus dioses como ellos tenían, porque en un libro que tenía lo leía y lo creía así como lo decía. Y que leída que fue la dicha carta el dicho su padre dijo a este declarante que la guardase que por ventura vendría tiempo que se hiciese lo que en ella decía. ${ }^{69}$

Este testimonio muestra cómo los maestros de escuela mayas se convirtieron en especies de ahkines modernos. ${ }^{70}$ Recogían las antiguas tradiciones, pero ya no las conservaban en los antiguos libros, sino en cartas escritas en caracteres latinos. Además, en este testimonio vemos el papel que tuvo la familia en la transmisión de los conocimientos tradicionales al maestro de escuela. El maestro de escuela es el hijo del cacique del pueblo. Por esta razón, la presión sobre el maestro de escuela es todavía más fuerte. Los franciscanos habían formado a jóvenes mayas, pero no se dieron cuenta de que el entorno al que los devolvían no había cambiado. Este contexto sociopolítico sería más fuerte que la reciente formación de los jóvenes maestros. Hasta los que intentaron ser fieles a las enseñanzas de los frailes se vieron obligados a participar en los ritos antiguos. Además, los religiosos reservaron a los maestros de escuela mayas una función muy delimitada, que no iba más allá de la enseñanza, sin darles la oportunidad de tener funciones religiosas. Estas limitaciones también deben tomarse en cuenta. Los maestros de escuela mayas acabaron buscando más responsabilidades de las que se les había asignado y encontraron en su religión tradicional las obligaciones religiosas que no se les quería confiar en la Iglesia católica. El problema tal vez residiera en el casi de esta frase de Landa: "haciéndolos casi compañeros de los religiosos en la predicación y la formación de los naturales". ${ }^{71}$ Ricard insiste en que el hecho de haber negado el sacerdocio a los indios fue uno de los principales fallos en la implantación de la Iglesia en Nueva España. ${ }^{72}$

${ }^{69}$ Ibid., I, p. 153.

${ }^{70}$ Según Matthew Restall, la función de maestro de escuela era "la que más se aproximaba, dentro de la legalidad colonial, a la posición del tradicional sacerdote maya". Restall, "Gaspar Antonio Chi: Bridging the Conquest of Yucatán", p. 13.

${ }^{71}$ DDQAMY, I, p. 189.

${ }^{72}$ Ricard, op. cit., p. 23. 


\section{Comunicación entre pueblos de indios}

Dado que muchas veces eran las únicas personas que sabían leer y escribir, el cacique y los principales recurrían a ellos cada vez que necesitaban ponerse en contacto con otros pueblos de indios o con la sociedad española. En varios testimonios de los juicios de Maní, encontramos casos de maestros de escuela llamados por los caciques para leer cartas. Ya vimos el ejemplo de Diego Tzab en Sanahcat. Otro ejemplo es el de Juan Couoh, maestro de la escuela de Yaxcaba, a quien el cacique Diego Pech también mandó llamar para que leyera una carta. En el testimonio siguiente —el de Lorenzo Ku, alguacil de Yaxcaba-, nos enteramos de que la carta mencionada era de Lorenzo Cocom, señor principal y cacique de Sotuta, difunto. Lo más interesante es que los dos testigos - Juan Couoh y Lorenzo Lu - dan el contenido de la carta en discurso directo. La carta contenía una crítica a los religiosos y una clara invitación a seguir practicando los ritos antiguos. ${ }^{73}$ Así, los maestros desempeñaron un papel esencial en el mantenimiento de los lazos sociopolíticos entre pueblos de indios a través de la comunicación por cartas. En el caso de idolatría de Maní, la noticia de la represión que ejercían los frailes se expandió rápidamente a los pueblos comarcanos a través de las cartas escritas por los maestros de escuela, de manera que se temía que surgiera una rebelión. En febrero de 1563, fray Antonio de Tarancón mandó una carta al padre fray Francisco de Bustamante para contarle los eventos del año anterior y analizarlos. En esta carta, no deja de mencionar el peligro que pudo representar esta capacidad de comunicación de los indios cuando dice que "venido el Provincial [fray Diego de Landa], trataron [Landa y el alcalde mayor Diego de Quijada] qué remedio se pondría en este tan gran mal como había en la tierra, porque toda ella estaba encartada". ${ }^{74}$ Los religiosos se dieron cuenta de que los indígenas estaban usando de manera totalmente autónoma este instrumento, la escritura alfabética, que ellos mismos les habían enseñado. Por otra parte, como ya dijimos, los franciscanos formaban a los indios en centros semejantes al de Maní y después los mandaban a otros pueblos que no eran siempre los de origen de los maestros. De alguna forma, favorecieron así la comunicación entre mayas en el periodo colonial. Además, los maestros de escuela parecen haberse desplazado por varios pueblos de manera autónoma. Y es que otro testimonio contenido en los juicios de Maní indica que durante las ceremonias de índole prehispánica se congregaban maestros de escuelas de diferentes pueblos:

Declara este declarante [Francisco Cen] que [...] se hallaron presentes en este sacrificio Luis Luit, maestro de escuela del pueblo de Sahcaba, y Antonio Pech, maestro que es de la escuela de Hoctun, y que entonces lo era de Hibi, y Juan Chan, maestro de la escuela de Xocchel. ${ }^{75}$

73 DDQAMY, I, p. 109.

${ }^{74}$ Ibid., II, p. 24.

${ }^{75}$ Ibid., I, p. 143. 


\section{Conocimiento de la escritura alfabética e integración social}

Aunque los religiosos no pretendieron transformar la jerarquía prehispánica, sino más bien apoyarse en ella para evangelizar a las masas indígenas, al introducir un nuevo tipo de enseñanza y de conocimientos, y al crear nuevas funciones sociopolíticas, influyeron en la organización de la sociedad indígena. El conocimiento del castellano, y más aun de la lectura y de la escritura, favoreció el acceso a responsabilidades tanto en los pueblos de indios como en la sociedad española.

El objetivo de los frailes

Los frailes franciscanos no quisieron utilizar la enseñanza de la lectura y de la escritura para modificar el orden social antiguo. Su objetivo era formar a los hijos de caciques y principales indios. Estos seguirían dirigiendo a los macehuales, pero dentro del marco de la vida cristiana. Esta elección se puede explicar, por una parte, por la mentalidad clasista que tenían los frailes y, por otra, por el deseo de ganarse el favor de la elite para que ésta transmitiera sus nuevos conocimientos al resto de la población. Cuando llegaron a Campeche y a Mérida, los franciscanos se dirigieron a los caciques. Les pidieron que les mandaran a sus hijos para educarlos. Pero la realidad desbordó el objetivo inicial. En efecto, algunos caciques no mandaron a sus hijos, sino a criados o a esclavos. Estos recibieron la enseñanza de los frailes, lo que supuso un cambio en la estructura social ya que en la sociedad prehispánica estas personas nunca hubieran recibido tal instrucción. Según el testimonio de Lizana, los mayas originarios de la gente del común formados por los franciscanos llegaron a obtener puestos de responsabilidad en los pueblos de indios:

Y algunos señores caciques, temiendo lo que les habían dicho sus sacerdotes idólatras escondían sus hijos propios y en su lugar enviaban los hijos de sus criados y esclavos y como después fuesen muy buenos escribanos y cantores: los que vinieron fueron puestos por caciques y gobernadores y ganaron el señorío, perdiéndolo los encubiertos por se quedar hechos montaraces. ${ }^{76}$

Desgraciadamente, es difícil tener una idea precisa de la extensión de este fenómeno social. En el Libro de Chilam Balam de Chumayel encontramos muchas referencias a la destrucción de los linajes gobernantes y al surgimiento de una nueva clase de dirigentes llamados "usurpadores". Es interesante notar que los autores de este libro asocian claramente la llegada del cristianismo con estos trastornos sociales. Así dice el "Libro de los Linajes":

Solamente por el tiempo loco, por los locos sacerdotes fue que entró a nosotros la tristeza, que entró a nosotros el "cristianismo".....] Fue el principio de la obra de

${ }^{76}$ Lizana, op. cit., p. 150. 
los españoles y de los "padres", el principio de usarse los caciques, los maestros de escuela y los fiscales. ${ }^{77}$

Tal testimonio muestra que, aunque no lo quisieron los religiosos, su enseñanza supuso cambios políticos y sociales. Tal vez los mismos frailes fueron incapaces de medir estos cambios por su conocimiento incompleto de la organización maya prehispánica. Sin embargo, tales cambios no pasaron desapercibidos para los mayas, sobre todo para la clase dirigente que, en algunos casos, llegó a ser despojada de sus antiguas funciones. Los autores del "Libro de los Linajes" explican estos trastornos por la decadencia en que cayó la enseñanza tradicional. El nuevo tipo de enseñanza dada por los religiosos ya no correspondía a la naturaleza sagrada que tenía la enseñanza de los ahkines en tiempos prehispánicos: "No había ya buenos Sacerdotes que nos enseñaran. [...] Eso es el origen de nuestra muerte. [...] No había Alto Conocimiento, no había Sagrado Lenguaje, ni había Divina Enseñanza en los sustitutos de los dioses que llegaron aquí". ${ }^{78}$ Esta cita muestra hasta qué punto el mero hecho de introducir un nuevo tipo de enseñanza significó una profunda alteración de la organización sociopolítica maya. No sólo originó la introducción de nuevas funciones dentro de la sociedad, como la de maestros de escuelas, sino que también significó un cambio de cultura más general, al pasar de un tipo de conocimiento de carácter sagrado e iniciático a un conocimiento más pragmático, a pesar de estar también vinculado con lo divino. En efecto, el conocimiento dado por los frailes a los mayas ya no les abría la puerta de lo sagrado como era el caso en tiempos prehispánicos, sino que más bien los conducía a responsabilidades no siempre muy altas dentro de la jerarquía de los pueblos de indios.

Integración en los pueblos de indios

¿Cuáles fueron las funciones a las que tuvieron acceso los mayas formados por los frailes? Examinando los procesos de idolatría de 1562, nos damos cuenta de que existen dos categorías de funciones abiertas a los mayas que sabían leer y escribir su propio idioma: la primera es la de maestro de escuela en pueblos de indios, de la cual ya hemos hablado; y la segunda, la de mozo de escuela. El maestro de escuela estaba encargado de la enseñanza religiosa de los niños del pueblo en el cual residía. Una de las declaraciones de los juicios de Maní contiene una definición precisa de la función del maestro de escuela: "[Juan Couoh] es natural del pueblo de Tanuz y al presente vive en el pueblo de Yaxcaba [...] y allí tiene el cargo de enseñar a los muchachos de la iglesia de ocho años a esta parte". ${ }^{79}$ Justo debajo del maestro de

\footnotetext{
${ }^{77}$ Mediz Bolio, op. cit., p. 30. Según esta cita, las funciones de maestro de escuela y de fiscal de doctrina eran distintas. Pero, como ya hemos expuesto anteriormente, parece que las dos funciones eran similares. Véase el apartado "Maestros mayas en los pueblos de indios" del presente artículo.

${ }^{78}$ Ibid., p. 36.

${ }^{79}$ DDQAMY, I, p. 103.
} 
escuela estaban los mozos de escuela. Eran los alumnos privilegiados de los maestros de escuela. Los formaban estos últimos y, a cambio, ellos les ayudaban en las tareas de enseñanza religiosa. Por ejemplo, en 1562 Juan Couoh llevaba más de seis años trabajando como maestro de escuela en el pueblo de Yaxcaba. Formó a Lorenzo Cocom, natural de Maní. Los religiosos mandaron a Lorenzo Cocom a Yaxcaba y, después de haber sido mozo de escuela en este pueblo, llegó a ser maestro de escuela. ${ }^{80}$

Las funciones de maestro y mozo de escuela estaban estrechamente vinculadas con los frailes. Los maestros de escuela debían servir de intermediarios entre los frailes y los indios en los pueblos de indios. Tenían que informar a los religiosos de los casos de idolatría y ayudarles a conocer mejor a los naturales, ya que los frailes sólo los podían atender de vez en cuando. Algunos mayas cumplieron con las expectativas de los religiosos. Sabemos que fue gracias a dos mozos que las idolatrías fueron descubiertas en el pueblo de Maní. Sin embargo, la mayoría de los maestros de escuela y de los mozos de escuela se volcaron hacia los pueblos de indios más que hacia los frailes. En efecto, la función de maestro de escuela parece haber llegado a ser central en la organización sociopolítica de los pueblos de indios al principio del periodo colonial.

El conocimiento de la lectura y la escritura también pudo dar acceso a otras funciones dentro de los pueblos de indios, como las de gobernadores, alcaldes o alguaciles. El ya citado Pablo Paxbolón era hijo de los señores naturales de la región de Acalán y fue recogido desde su niñez por los religiosos y criado en el convento de San Francisco de Campeche. Posteriormente fue nombrado gobernador del pueblo de Tixchel. La carta de Diego de Landa del 9 de junio de 1562 es explícita acerca de la ascensión social permitida a los indios educados por los franciscanos:

Es venido a su noticia ser muy pocos fieles cristianos a causa de no lo ser algunos de sus caciques y principales y maestros de escuelas de quien pende su bien por haberse como se ha hecho confianza de ellos haciéndolos casi compañeros de los religiosos [...] y haciéndo de ellos su Magestad gobernadores, alcaldes y alguaciles y dándoles otros cargos y dictados. ${ }^{81}$

Este fragmento también constituye un ejemplo de la habilidad de Landa que pone en paralelo la responsabilidad de los religiosos y la de las autoridades civiles en la política seguida por ambas instituciones respecto a los indios. Landa recuerda que el rey también dio responsabilidades a los indios, de la misma manera que lo habían hecho los religiosos. Para él, las autoridades civiles compartían la responsabilidad del fracaso revelado por el descubrimiento de tan numerosos casos de idolatría en la provincia en 1562.

\footnotetext{
${ }^{80}$ Ibid., I, p. 112.

${ }^{81}$ Ibid., I, p. 192.
} 
Además de dar acceso a puestos en los pueblos indígenas, el conocimiento de la lectura y de la escritura también permitía ocupar determinados cargos dentro de la sociedad española. Una vez más citaremos el ejemplo de Gaspar Antonio Chi, quien ocupó varios cargos administrativos a lo largo de su vida. Por una parte, ocupó funciones relacionadas con los franciscanos: fue intérprete de los religiosos, escribió sermones en lengua maya, fue notario de Landa en los juicios inquisitoriales de Maní, maestro de predicación en la catedral de Mérida, predicó la Bula de la santa cruzada entre los indios. Los oficiales reales también necesitaron de sus servicios. Desde 1552 fue intérprete general en los juzgados. El gobernador Diego de Santillán lo nombró teniente de gobernador en los pueblos de Maní y Tacul por tres años, de 1571 a $1573 .{ }^{82}$ Gaspar Antonio destaca en la historia social de los mayas de Yucatán por la continuidad y la multiplicidad de los cargos que ocupó y también por sus excepcionales competencias: no sólo sabía latín, castellano, maya y náhuatl, sino también canto llano y canto de órgano.

Pero si nos fijamos atentamente en los documentos, nos damos cuenta de que otros mayas llegaron también a desempeñar funciones relacionadas con la "república" española. El requisito indispensable para conseguir tales funciones era saber leer y escribir no sólo el maya, sino también el castellano. Lo que nos indica que existían varios niveles de formación en las escuelas franciscanas. Los maestros de escuela sólo aprendían a escribir en caracteres latinos su propia lengua. No era parte de su formación el castellano. Por eso, casi todos los maestros de escuela interrogados en los procesos de Maní supieron firmar pero necesitaron la ayuda de un intérprete. Los pocos que aprendían el castellano se distinguían dentro de la jerarquía india y algunos llegaron a ocupar cargos importantes en la sociedad colonial, como intérpretes o escribanos. Por ejemplo, Jorge Xiu, indio natural de Maní, fue intérprete en el informe sobre la idolatría realizado en septiembre de 1562 en el pueblo de Homun. ${ }^{83}$

En 1573, el gobernador Diego de Santillán mandó que se edificara un monasterio en Santa María de Cozumel y que se tomara posesión del sitio con una procesión y una cruz de madera. En esta ocasión se nombró a "Agustin Ytza, nahuatlato y ladino en la lengua castellana y en la de los indios" para que explicara la toma de posesión a los indios de la isla. ${ }^{84}$ Así que, como dice Restall, "los intérpretes eran ya ignorados, ya valorados y reconocidos por su labor exigente y eficaz. [...] Si [...] lograban sobrevivir, solían alcanzar un estatus en la sociedad colonial normalmente vedado a todos los indígenas, excepto a los nobles de ma-

\footnotetext{
${ }^{82}$ AGl, México, 104 y 105. "Probanzas de Gaspar Antonio Chi. Para una biografía de Gaspar Antonio", véase Restall, op. cit., pp. 6-21.

83 DDQAMY, op. cit., I, pp. 135-162.

${ }^{84}$ AGl, México, 369, Ramo 1. "Auto de don Diego de Santillan sobre iglesias en isla de Cozumel", 27 de agosto de 1573.
} 
yores privilegios". ${ }^{85}$ De la misma manera encontramos que Baltazar de Herrera, clérigo presbítero beneficiado del partido de Peto, empleó a Fernando Uxul como notario en el informe sobre idolatrías que hizo en dicho partido en $1598 .{ }^{86}$ En este caso es interesante ver cómo la participación de los mayas en la elaboración de los informes proporciona mayor riqueza a las declaraciones, ya que los notarios mayas, por una parte, solían transcribir mayor cantidad de palabras en su idioma y, por otra, reproducían con más frecuencia fragmentos de declaraciones de indios en discurso directo.

Así, el conocimiento de la escritura permitió que los mayas accedieran generalmente a algunos cargos en un ámbito local, es decir, en la esfera de su propio pueblo, y por un periodo de tiempo más bien corto. En la ciudad de Mérida los mayas también consiguieron algunos cargos tanto en la escuela franciscana como en la catedral. En una carta en la cual fray Antonio de Tarancón reprochaba al obispo fray Francisco de Toral su actitud laxista con respecto a los indios, a quienes daba más crédito que a los frailes, Tarancón se refería a tres muchachos, especificando que "el uno era lector de la mesa, y el otro, portero, y el más chico, el mayor trabajo que tenía era ir por las tortillas cuando habíamos de comer". También aludía a "cantores de la escuela" y al "mozo principal de la escuela". ${ }^{7}$ Así, vemos que algunos mayas colaboraban con los franciscanos en el campo de la enseñanza, aunque se tratara de funciones subalternas. Con el paso del tiempo, los españoles llegaron a quejarse de la presencia de los indios en la iglesia de Mérida, por ser "cosa muy indecente". Y cuando llegó a Mérida el obispo fray Juan de Izquierdo encontró la iglesia catedral "muy falta de servicio así en el coro como en el altar pues hasta entonces era servido el altar de indios y los dichos indios muchachos ayudaban a las misas y llevaban los ciriales y los demás oficios de la iglesia por no haberse aplicado ni inclinado muchachos españoles a la iglesia”. Por eso, en 1599 el obispo fundó un estudio, en el cual empleó a Melchior Telles como preceptor para formar jóvenes criollos que pudieran reemplazar a los indios en el servicio de la catedral de Mérida. ${ }^{88}$

\section{Consideraciones finales}

Hemos tratado de mostrar cómo el aprendizaje de la escritura alfabética tuvo repercusiones en la vida social de los mayas en los primeros tiempos de la Colonia. No sólo fue una condición de acceso a cargos en los pueblos de indios, sino también a cargos más directamente vinculados con la sociedad española. Con el

\footnotetext{
${ }^{85}$ Restall, op. cit., p. 135.

${ }^{86}$ AGl, México 292. "Probanza de Baltazar de Herrera, clérigo presbítero beneficiado del partido de Petú, Yucatán. Información sobre idolatrías”, 1598.

87 DDQAMY, II, pp. 16-21.

${ }^{88}$ AGl, México, 369. "Información del obispo de Yucatán Juan de Izquierdo”, 4 de julio de 1599 , fols. 290-323.
} 
paso del tiempo y el crecimiento de la población española y criolla en Yucatán, la presión sobre los cargos que tenían los indios aumentó y fueron reemplazados por personal blanco. Paralelamente, el discurso sobre los indios también cambiaba y crecía el recelo y la desconfianza acerca de sus capacidades, tal vez como justificación para ya no reservarles sitio en la sociedad colonial. En los pueblos de indios la situación era diferente, ya que los mayas gozaban de más autonomía. Los religiosos siguieron formando a jóvenes mayas para mandarlos a doctrinar en distintos pueblos. Tal estrategia favoreció la comunicación entre los pueblos indígenas. Así que los mayas no sólo usaron el conocimiento de la escritura alfabética para salvaguardar su historia y sus conocimientos, sino también para mantener la cohesión política entre sus pueblos. En estos años tempranos de la época colonial, el maestro de escuela se convirtió en una figura central en la vida de los pueblos de indios, precisamente por estos conocimientos que lo colocaban entre las dos culturas. La comparación de los cuadros 1, 2 y 3 (1562) con los cuadros 4 y 5 (1597-1598), incluidos en el apéndice, parece indicar que fueron cada vez más numerosos los caciques que sabían leer y escribir a finales del siglo xvi, de manera que podemos suponer que la figura del maestro de escuela dejó de tener tanta importancia en la vida política de los pueblos de indios del siglo xvII. 



\section{APÉNDICE \\ Mayas que sabían escribir en algunos pueblos de Yucatán según su estatuto social}

\section{CUADRO 1}

Sotuta, Kanchunup, Mopila, Sahcaba, Yaxcaba, Usil, Tibolon (1562)

\begin{tabular}{|c|c|c|c|c|}
\hline Nombre / Apellido & Pueblo & Edad & Estatuto social & Firma \\
\hline Diego Te & Sotuta & & Natural del pueblo & No supo \\
\hline Francisco Ix & Sotuta & & Natural, principal de un barrio & No supo \\
\hline Juan Camal & Sotuta & & Principal del pueblo & No supo \\
\hline Agustin Che & Sotuta & & Principal del pueblo & No supo \\
\hline Antonio Pech & Sotuta & & Mozo de la escuela del pueblo & Firmó \\
\hline Melchor Canche & Sotuta & & Mozo de la escuela y aguacil & Firmó \\
\hline Gaspar Hau & Kanchunup & & Principal del pueblo & No supo \\
\hline Diego Keuel & Kanchunup & & Natural del pueblo & No supo \\
\hline Francisco Balam & Kanchunup & & Principal del pueblo & No supo \\
\hline Francisco Pacab & Kanchunup & & Vecino del pueblo & No supo \\
\hline Francisco Pot & Kanchunup & & Natural del pueblo & No supo \\
\hline Francisco Canche & Kanchunup & & Maestro de escuela del pueblo & Firmó \\
\hline Pedro Huhul o Huh & Kanchunup & & Principal del pueblo & No supo \\
\hline Juan Camal & Mopila & & Ahkin y principal del pueblo & No firmó \\
\hline Francisco Ch`oben & Mopila & & Maestro de escuela del pueblo & Firmó \\
\hline Francisco $\mathrm{Na}$ & Mopila & & Principal del pueblo & No firmó \\
\hline Francisco Chuc & Sahcaba & & Ahkin & No firmó \\
\hline Francisco Mo & Sahcaba & & Mozo de escuela & Firmó \\
\hline Juan Couoh & Yaxcaba & & Natural de Tanuz, maestrescuela & Firmó \\
\hline Lorenzo Ku & Yaxcaba & & Natural y alguacil del pueblo & Firmó \\
\hline Juan Tzek & Yaxcaba & & Natural y cacique & No firmó \\
\hline Juan Ku & Yaxcaba & & Principal del pueblo & No firmó \\
\hline Lorenzo Cocom & Yaxcaba & & Maestrescuela del pueblo & Firmó \\
\hline Juan Pech & Usil & & Maestrescuela del pueblo & Firmó \\
\hline Melchor Chan & Usil & & Principal del pueblo & No firmó \\
\hline Juan Kantun & Usil & & Alguacil del pueblo & No firmó \\
\hline Francisco Kantun & Usil & & Maestrescuela del pueblo & Firmó \\
\hline Juan Cocom & Tibolon & & Natural y principal del pueblo & No firmó \\
\hline Francisco Tuz & Tibolon & & Natural del pueblo & No firmó \\
\hline Francisco Camal & Tibolon & & Vecino y natural & No firmó \\
\hline Juan May & Tibolon & & Maestro de la escuela & Firmó \\
\hline Gaspar Kumun & Tibolon & & Maestro de la escuela & Firmó \\
\hline
\end{tabular}

Fuente: DDQAmy, I, pp. 71-129. "Procesos contra los indios idólatras de Sotuta, Kanchunup, Mopila, Sahcaba, Yaxcaba, Usil y Tibolon”, agosto de 1562. 


\section{CUADRO 2}

Hocaba, Sanahcat, Tixcamahel, Tahmek (1562)

\begin{tabular}{|l|l|l|l|l|}
\hline Nombre / Apellido & Pueblo & Edad & Estatuto social & Firma \\
\hline Diego Chuc & Hocaba & & Natural del pueblo & No firmó \\
\hline Juan Dzul & Hocaba & & Natural del pueblo & No firmó \\
\hline Francisco Cen & Hocaba & & Principal del pueblo & No firmó \\
\hline Juan Luit & Hocaba & & Vecino y natural del pueblo & No firmó \\
\hline Francisco Yam & Hocaba & & Vecino del pueblo & No firmó \\
\hline Lorenzo Couoh & Hocaba & & Natural del pueblo & No firmó \\
\hline Diego Tzab & Sanahcat & & Cacique y señor del pueblo & No firmó \\
\hline Juan Tzabnal & Sanahcat & & Hermano del precedente & No firmó \\
\hline Diego Tzab & Sanahcat & & Hijo de Diego Tzab, \\
& maestro escuela & Firmó \\
\hline Luis Ku & Huhi & & Vecino y natural del pueblo & No firmó \\
\hline Alonso Chan & Hocaba & & Principal y alguacil del pueblo & No firmó \\
\hline Juan Ku & Tixcamahel & & Vecino y natural del pueblo & No firmó \\
\hline Esteban Be & Tixcamahel & & Natural y alguacil del pueblo & No firmó \\
\hline Francisco Can & Tixcamahel & & Natural del pueblo & No firmó \\
\hline Andres Pech & Tahmek & & Vecino y natural & No firmó \\
\hline
\end{tabular}

Fuente: DDQAmY, I, pp. 135-162. Informe realizado en el pueblo de Homun sobre la idolatría de los indios, septiembre de 1562.

\section{CUADRO 3}

\section{Maní (1562)}

\begin{tabular}{|l|l|l|l|l|}
\hline Nombre / Apellido & Pueblo & Edad & Estatuto social & Firma \\
\hline Agustín Tuz & Maní & & Natural de Yicman y alguacil de Maní & No \\
\hline Luis Be & Maní & & Natural del pueblo & Firmó \\
\hline Juan Yc & Maní & & Natural del pueblo & No \\
\hline
\end{tabular}

Fuente: DDQAMY, I, pp. 174-177. "Información hecha por el doctor Quijada contra el obispo sobre haber dicho que le había pesado lo que se había hecho contra los indios en quitarles los ídolos”, Mérida, 18 de septiembre de 1562. 
CUADRO 4

Calotmul, Peto $(1598)^{89}$

\begin{tabular}{|l|l|l|l|l|}
\hline Nombre / Apellido & Pueblo & Edad & Estatuto social & Firma \\
\hline Melchoir Xiu & Calotmul & 35 & Gobernador del pueblo & Firmó \\
\hline Francisco Che & Calotmul & 50 & Alcalde del pueblo & No \\
\hline Juan Ru & Calotmul & 30 & Alcalde del pueblo & No \\
\hline Gaspar Col & Peto & 25 & Vecino del pueblo & No \\
\hline Melchior Zul & Peto & 30 & Natural y vecino del pueblo & No \\
\hline Ana Quime & Peto & 50 & Vecina del pueblo & No \\
\hline Catalina Zul & Peto & 25 & Vecina del pueblo & No \\
\hline Juan Tun & Peto & 30 & Vecino del pueblo & No \\
\hline Pedro Hek & Peto & 40 & Vecino y principal & Firmó \\
\hline Pablo Camal & Peto & 30 & Gobernador del pueblo & Firmó \\
\hline Juan Tec & Peto & 28 & Idólatra & No \\
\hline Agustín Zul & Peto & 40 & Idólatra & No \\
\hline Pedro Pix & Peto & 30 & Idólatra & No \\
\hline Pedro Col & Peto & 20 & Idólatra muñidor & No \\
\hline Juan Na & Peto & 35 & Idólatra & No \\
\hline Andres Chim & Peto & 30 & Idólatra & No \\
\hline Francisco Pech & Peto & 50 & Idólatra & No \\
\hline
\end{tabular}

Fuente: AGI, México, 292. "Probanza de Baltazar de Herrera, clérigo presbítero beneficiado del partido de Peto, Yucatán. Información sobre idolatrías”, 1598.

\section{CUADRO 5}

Calotmul, Zucab, Nabalon, Tiquibalon (1597) $)^{90}$

\begin{tabular}{|l|l|l|l|l|}
\hline Nombre / Apellido & Pueblo & Edad & Estatuto social & Firma \\
\hline Melchoir Xiu & Calotmul & 40 & Gobernador del pueblo & Firmó \\
\hline Luis Zol & Calotmul & 40 & Maestro de capilla y escribano & Firmó \\
\hline Diego Chan & Zucab & & $\begin{array}{l}\text { Gobernador del pueblo, ladino, } \\
\text { nombrado notario del padre Arroyo }\end{array}$ & Firmó \\
\hline Juan Uz & Calotmul & 50 & Vecino y cacique & Firmó \\
\hline Francisco Chan & & 24 & Ayudó al padre Arroyo como fiscal & Firmó \\
\hline Marcos Copul & Nabalon & 35 & Cacique y señor natural & Firmó \\
\hline Diego Baz & Tiquibalon & 60 & $\begin{array}{l}\text { Había sido intérprete y notario } \\
\text { del padre Arroyo }\end{array}$ & Firmó \\
\hline
\end{tabular}

Fuente: AGI, México, 294. "Probanza de Antonio de Arroyo, clérigo presbítero beneficiado del partido de Peto, Yucatán. Información sobre idolatrías”, 1597.

${ }^{89}$ Para transcribir los nombres de los pueblos de indios citados en la probanza de Baltazar de Herrera se ha usado el índice analítico de Yucatán, población y encomienda bajo los Austrias de Manuela Cristina García Bernal, 1978, pp. 561-595. Calotmul también se encuentra bajo la forma de Calatamud o Calatmud.

${ }^{90}$ Zucab también se encuentra como Kukab y Nabalon como Nabalam. En el índice de Manuela Cristina García Bernal hemos encontrado una referencia a Tequinavalon que podría ser el mismo pueblo que Tiquibalon citado en la probanza de Antonio de Arroyo. 


\section{BIBLIOGRAFÍA}

Acuña, René

2000 "Escritos mayas inéditos y publicados hasta 1578: testimonio del obispo Diego de Landa", Estudios de Cultura Maya, XXI: 165-179. México, unAm, IIFL, Centro de Estudios Mayas.

Arzápalo Marín, Ramón

2004 "El lenguaje del poder entre los mayas antiguos", La palabra florida. La tradición retórica indígena y novohispana, pp. 83-93, H. Beristáin y G. Ramírez Vidal (comps.). México: UNAM, IIFL.

Blom, Frans

1928 "Gaspar Antonio Chi, interpreter", American Anthropologist, 30 (2): 250-262. Menasha [Wisconsin]: American Anthropological Association.

Bracamonte y Sosa, Pedro

2001 La conquista inconclusa de Yucatán. Los mayas de la montaña, 1560-1680. Mérida: Colección Peninsular.

Brocamonte y Pedro Sosa y Gabriela Solís Robleda

1996 Espacios mayas de autonomía. El pacto colonial en Yucatán. Mérida: Universidad Autónoma de Yucatán.

Chuchiak, John F.

2000 "Pre-conquest ah kinob in a colonial World: the Extirpation of Idolatry and the Survival of the Maya Priesthood in colonial Yucatan, 1563-1697", 50th International Congress of Americanists: Five Hundred Years of Maya Survivalism. 10-15 de julio de 2000. Varsovia.

Clendinnen, Inga

1982 "Disciplining the Indians: Franciscan Ideology and Missionary Violence in Sixteenth Century Yucatan”, Past and Present, 94: 27-48. Oxford: Oxford University Press.

1986 Ambivalent Conquest: Mayas and Spaniards, 1517-1570. Cambridge [Reino Unido]: Cambridge University Press.

Don Diego Quijada, alcalde mayor de Yucatan, 1561-1565

1938 Edición de France Scholes V. y Eleanor Adams. México: Antigua Librería Robredo.

García Bernal, Manuela Cristina

1978 Yucatán, población y encomienda bajo los Austrias. Sevilla: Consejo Superior de Investigaciones Científicas, Escuela de Estudios Hispanoamericanos.

1982 "Los franciscanos y la defensa del indio yucateco", Temas Americanistas, 1: 8-16. Sevilla: Universidad de Sevilla.

1992 "Indios y españoles en Yucatán: utopía y realidad del proyecto coloniza- 
dor”, en Historia del Descubrimiento (1492-1556), tomo II, pp. 387-427. Madrid: Real Academia de la Historia.

García Icazbalceta, Joaquín

1954 Bibliografía mexicana del siglo XVI. México: FCE.

García Targa, Juan y Alfonso Gussinyer

2005 "Los primeros templos cristianos en el área maya: Yucatán y Belice, 15451585”, Estudios de Cultura Maya, XXV: 95-119. México: unAm, IIFL, Centro de Estudios Mayas.

Gómez Canedo, Lino

1977 Evangelización y conquista: experiencia franciscana en Hispanoamérica. México: Porrúa.

1982 La educación de los marginados durante la época colonial. Escuelas y colegios para indios y mestizos en la Nueva España. México: Porrúa.

González Cicero, Stella María

1978 Perspectiva religiosa en Yucatán, 1517-1571. México: El Colegio de México.

Gubler, Ruth

1992 "Manuscrito inédito del padre Juan Pedro de Herrera", Revista de la Universidad Autónoma de Yucatán, 7 (180): 25-29. Mérida: Universidad Autónoma de Yucatán.

Hillerkuss, Thomas

1993 "Los méritos y servicios de un maya yucateco principal del siglo xvı y la historia de sus probanzas y mercedes", Estudios de Historia Novohispana, 13: 9-25. México: UnAm, Instituto de Investigaciones Históricas.

Jakeman, M. Wells

1952 The 'Historical recollections' of Gaspar Antonio Chi. An early account of Ancient Yucatan, Provo [Utah]: s. e. (Archaelogy and Early History, 3).

Landa, Diego de, fray

1973 Relación de las cosas de Yucatán. México: Porrúa.

Lizana, Bernardo de, fray

$1988 \quad$ Historia de Yucatán. Madrid: Historia 16.

Martel, Patricia y Edmundo López de la Rosa

2006 "Than-uooh. Experiencias con la escritura maya yucateca prehispánica", Desacatos, 22: 93-108. Mérida: Centro de Investigaciones y Estudios Superiores en Antropología Social.

Mediz Bolio, Antonio (trad.)

1933 El libro de Chilam Balam de Chumayel. Mérida. 
Moreno Jería, Rodrigo

2006 "Metodología misional jesuita en la periferia austral de América", La misión y los jesuitas en la América Española, 1566-1767: cambios y permanencias, pp. 239-263, J. Hernández Palomo y R. Moreno Jería (coords.). Sevilla: Consejo Superior de Investigaciones Científicas.

Motolinía, Toribio de Benavente, fray

$1988 \quad$ Historia de los indios de la Nueva España. Madrid: Alianza.

Relaciones histórico-geográficas de la Gobernación de Yucatán

1983 Edición de Mercedes de la Garza, Ana Luisa Izquierdo, María del Carmen León y Tolita Figueroa. México: unAm, IIFL, Centro de Estudios Mayas, 2 vols.

Restall, Matthew

2002 "Gaspar Antonio Chi: Bridging the Conquest of Yucatán", The human tradition in Colonial Latin America, pp. 6-21, A. Kenneth (ed.). Wilmington [Delaware]: Scholarly Resources.

2004 Los siete mitos de la conquista española. Barcelona: Paidós.

Rodríguez Lorenzo, Sergio

1999 "Un capítulo de la historia de la escritura en América: la enseñanza de las primeras letras a los indios en el siglo xv”, Anuario de Estudios Americanos, LVI (1): 41-64. Sevilla: Consejo Superior de Investigaciones Científicas, Escuela de Estudios Hispanoamericanos.

Ricard, Robert

1999 La conquista espiritual de México. México: FCE.

Rubio Mañé, J. Ignacio

1942 Archivo de la historia de Yucatán, Campeche y Tabasco. México: Imprenta Aldina, Robredo y Rosell, 3 vols.

Ruiz Medrano, Ethelia

1999 "Códices y justicia: los caminos de la dominación", Arqueología Mexicana, VII (38): 45-50. México: InAH, Raíces.

Solís Robleda, Gabriela

1994 "Religión y sociedad maya al tiempo de la Conquista", Boletín de la UADY, 19 (114): 5-22. Mérida. Universidad Autónoma de Yucatán.

s. f. $\quad$ La instrucción básica en Yucatán. De la conquista al Segundo Imperio. En prensa.

Strecker, Matthias y Artieda Jorge

1978 "La Relación de algunas costumbres de Gaspar Antonio Chi, 1582". Estudios de Historia Novohispana, 6: 1-25. México: unAm, Instituto de Investigaciones Históricas.

Tozzer, Alfred M.

1941 Landa's 'Relación de las cosas de Yucatán'. Cambridge [Massachussets]: Harvard University, Peabody Museum of American Archaelogy and Ethnology. 